\title{
Intra-abdominal suture granulomas masquerading as colon carcinoma: a case report
}

\begin{abstract}
Suture granuloma is a rare benign mass which represents a non-allergic foreign body granulomatous tissue reaction against the suture material that is surgically instituted in the body. We present a case of caecum suture granulomas in a 45-year-old man which was clinico-radiologically misdiagnosed as colon carcinoma. A high index of clinical suspicion of this uncommon surgical complication and a precise preoperative diagnosis is essential to avoid unnecessary extensive surgical interventions.
\end{abstract}

Keywords: colon cancer, foreign body, surgery, granuloma, sutures
Volume 3 Issue 4 - 2018

\author{
Sonam Sharma, Sonu Kalyan \\ Department of Pathology, Kalpana Chawla Government Medical \\ College, Karnal, Haryana, India
}

Correspondence: Sonam Sharma, Department of Pathology, Kalpana Chawla Government Medical College, Karnal, Haryana, India,Tel 99998413 93, Email drsonamsharma@gmail.com

Received: May 30, 2018 | Published: September 21, 2018

\section{Introduction}

A foreign body granulomatous reaction is the end-stage response of the inflammatory and wound-healing process to an immunologically inert substance which may be endogenous or exogenous in origin. ${ }^{1}$ The material which is not native to the human body like sutures, silicone gel, surgical glove starch powder, paraffin, cotton gauze, talc, wood, cactus spine etc. is introduced into the body during surgical procedures or trauma leading to its recognition as foreign by antigen presenting cells (tissue macrophages), which surrounds the material to quarantine it from the surrounding uninvolved tissue. Amongst all the reactions, suture-related foreign body reaction also known as suture granuloma has drawn attention from every branch of medicine according to the pertinent world literature. ${ }^{2-11}$ Both the suture materials i.e. absorbable or non-absorbable, can elicit such a reaction. ${ }^{6,12}$ However, suture granuloma is formed more commonly due to non-absorbable suture material and can occur anywhere in the body. ${ }^{2,7,13}$ It tends to develop in early post-operative period, nevertheless its occurrence even after several years following a surgery has been documented. ${ }^{5,14}$ Abdominal cavity suture granuloma is a disadvantage following usually any abdominal surgery. It is utmost important to timely diagnose this entity as it can mimic other abdominal conditions like a perforation, an abscess or a tumor, leading to inessential aggressive therapeutic interventions and further complications. ${ }^{15-19}$ We describe one such unusual case of intra-abdominal suture granulomas in a 45 -year-old male which simulated as a colon cancer.

\section{Case report}

A 45-year-old Indian illiterate male from a rural background came to the surgery outpatient department with the chief complaints of intermittent colicky pain abdomen and occasional passage of mucus and blood per rectum since last 6 months. He also had appetite and weight loss. His past medical history was significant as he had an abdominal surgery for acute pain abdomen a year back at a private center; however, the medical records pertaining to it were lost by the patient. His general physical examination revealed pallor while his systemic examination was within normal limits. Routine hematological investigations showed microcytic hypochromic red blood cell picture. His biochemical and microbiological tests revealed no abnormality. Radiological investigations included X-ray chest which was normal. Computed tomography scan exhibited circumferential mural thickening of the ascending colon wall and a mass in the caecum giving an impression of primary carcinoma of the colon or its recurrence in the region of the previously operated site. In view of a high degree of clinical and radiological suspicion of carcinoma colon, an exploratory laparotomy with resection of the involved bowel segment was performed. The specimen was sent for histopathological examination. Grossly, an intestinal segment of $36 \mathrm{~cm}$ length consisting of a part of ascending colon, caecum, appendix and a part of ileum was received. Serosal surface of the intestinal segment revealed areas of congestion. A mass was seen in the caecal region (Figure 1A). On cut section, an irregular grey white solid mass was obliterating the lumen of caecum. It measured $7 \times 5 \times 4.5 \mathrm{~cm}$ in size and was situated approximately $3 \mathrm{~cm}$ away from distal resected margin. On further, serial sectioning through the mass, multiple sutures were seen which were embedded in it (Figure 1B). The mucosa of rest of the intestinal segment and the attached appendix were unremarkable. Microscopic examination of the sections from the grey white mass showed granulomatous reaction marked by histiocytes and numerous foreign body type giant cells in the wall of the intestine (Figure 2A). Refractile suture material was seen in aggregates and scattered amidst the inflammatory infiltrate surrounded by these giant cells (Figure 2B $\&$ Figure 2C). Some of the giant cells were seen engulfing the suture material in their cytoplasm (Figure 2D). There was no evidence of caseous necrosis or any malignancy. Microsections examined from rest of the intestine, cut margins and appendix were unremarkable. Based on these histological findings, a final diagnosis of caecum suture granulomas was made. The post-operative period of the patient was uneventful and on follow-up, he is doing well with no fresh complaints. 


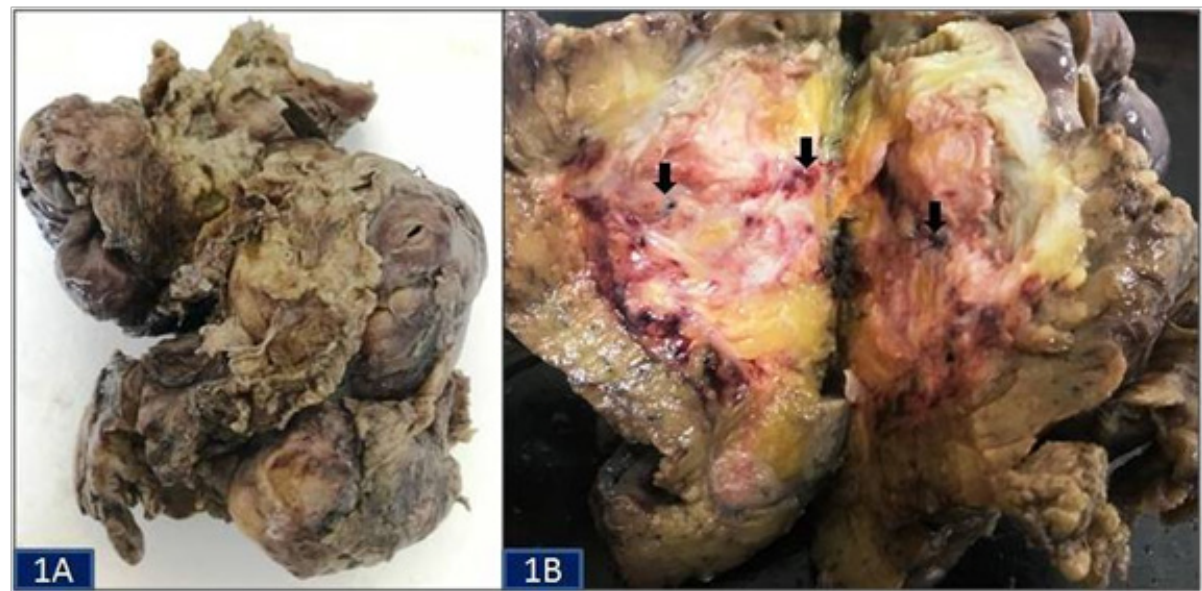

Figure I(A) Resected intestinal segment showing a caecal mass. (B) The cut section of the mass is solid grey white and reveals surgical sutures (arrows).

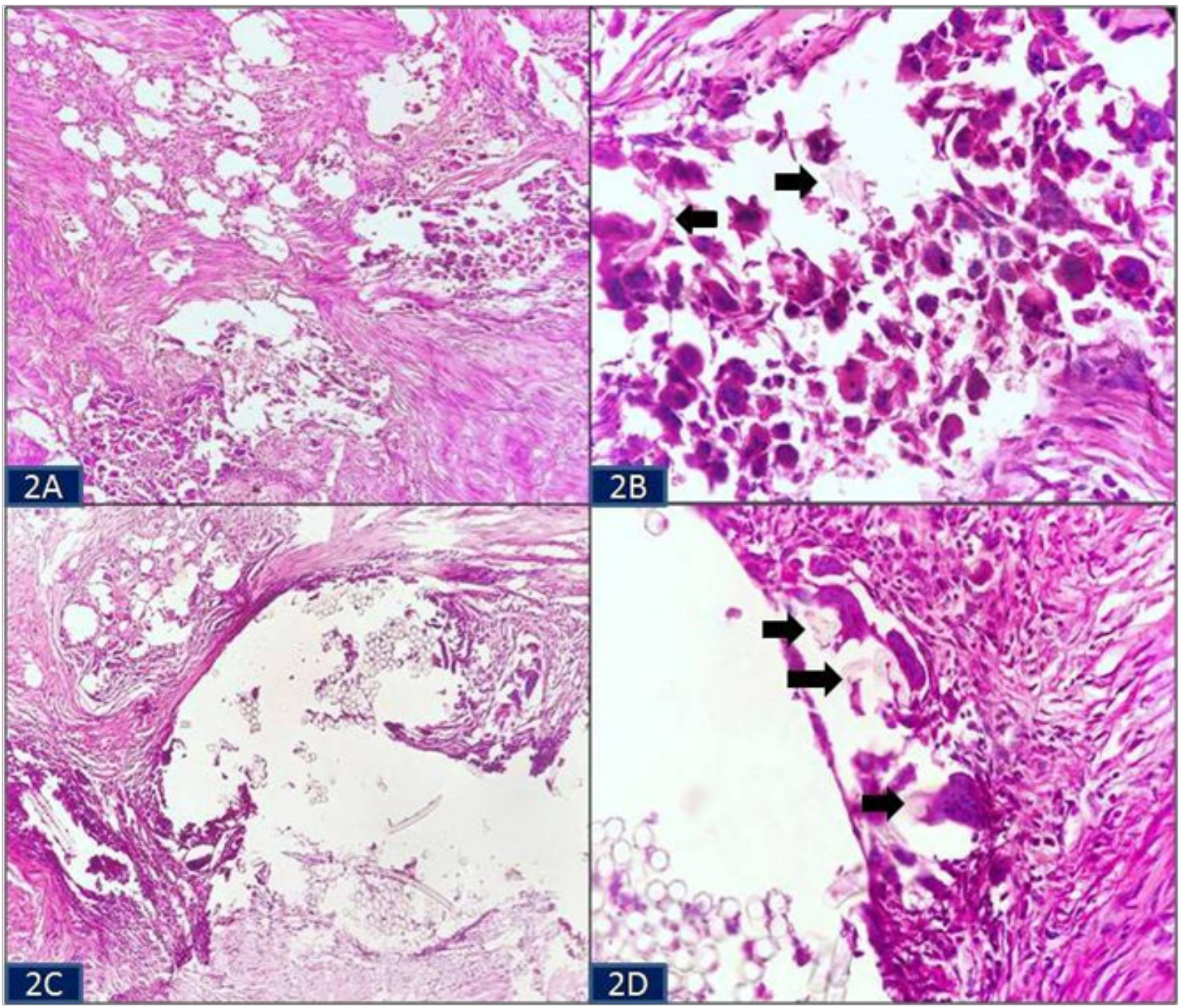

Figure 2(A) Inflammatory granulomas in the muscularis layer of the caecum (H\&E, $x 40)$. (B) Numerous multinucleated foreign body type giant cells with interspersed semitransparent and glossy surgical sutures (Arrows) $(H \& E, \times 200)$. (C) Suture granulomas $(H \& E, \times 40)$. (D) Giant cells engulfing the suture material (Arrows) (H\&E, x200). 


\section{Discussion}

Surgery is a medical specialty that uses operative manual and instrumental techniques on a patient to investigate or treat a pathological condition. Since decades numerous surgical procedures have been a boon for modern sciences. However, they have their own drawbacks and side-effects which warrants attention by the clinicians, so as to reduce the morbidity and mortality of the patients. One such major complication of surgeries is that it invariably exposes the human body to a large number of foreign materials. The substances like sutures, talc/starch from surgical gloves, sponge, gauze, lint, cellulose fibres from surgical gowns, surgical clips, oxidised cellulose from hemostatic agents and mineral oil/paraffin etc. when introduced into the human body induce an inflammatory and foreign body giant cell reaction. However, depending upon the nature and the extent of the reaction produced by these foreign bodies, they may cause variety of lesions such as intra-abdominal adhesions (secondary to suture and talc granulomas), space-occupying lesions (especially in the brain), tumor masses (textilomas or gossypibomas), or even lesions mimicking tumor metastasis and recurrence at previously operated sites of cancer patients. ${ }^{19-22}$

The development of a foreign body granuloma from a suture material in the abdomen is a relatively uncommon condition that most commonly occurs in response to silk and polyfilament threads which are considered to be non-absorbable materials. ${ }^{7,23}$ These granulomas are usually encountered in patients who have undergone recent abdominal surgery. The suture material itself and the ischemia caused by tightening of the sutures can initiate an inflammatory reaction. This depends on the rate of resorption of the suture material by the body, the highest rate occurring in the first year post-operatively. Therefore, many authors have documented that the time duration between the operation and the occurrence of the suture granulomas can vary from months to several years apart from just being an immediate postoperative finding.

The clinical presentation of intra-abdominal suture granuloma is non-specific and diverse as it can lead to formation of adhesions or abscess, cause perforation, peritonitis or can present as a slow growing solid painless mass and masquerade as a malignancy. ${ }^{20}$ Therefore, its diagnosis cannot be relied only on the history and the clinical findings of the patients. Radiological investigations play an important role in reaching a final diagnosis in most of the gasterointestinal disorders. But in cases of foreign body granulomas, although the imaging modalities such as ultrasonography, computed tomography, magnetic resonance imaging and 2-deoxy-2-[fluorine-18] fluoro-D-glucose positron emission tomography are useful in detecting the foreign bodies, a few cases lack the typical radiological findings, and can lead to a diagnostic conudrum. ${ }^{23-27}$ Intra-abdominal suture granulomas radiologically are mainly mistaken as a primary malignancy or as the recurrence of the previously diagnosed cancer as mentioned by various researchers. ${ }^{3,4,28-31}$ Therefore, its definite diagnosis is only made after the surgical excision of the lesion followed by histopathological examination. Histopathology shows a granulomatous response marked by histiocytes and foreign body type giant cells surrounding and engulfing the suture material. Double refraction under polarized light microscopy is very helpful in localizing it. Nevertheless, the surgery in such cases also allows eradication of the inflammation whereas histopathology reduces the further need of unnecessary interventions. In the present case, the clinical and radiological findings were quite misleading as based on them a diagnosis of primary colon carcinoma or its recurrence was made. However, it was only on the histopathology of the resected segment of intestine that it turned out to be a case of caecum suture granulomas.

\section{Conclusion}

Intra-abdominal suture granuloma is a rare but potentially serious complication which should be kept in mind while dealing with patients having prior history of any abdominal surgery especially in cancer patients. It has unspecified clinical features and radiological investigations may misdiagnose this entity so, an accurate pre-operative diagnosis via timely surgical intervention and histopathological examination is mandatory in such patients so as to avoid the suspicion of malignancy and to reduce the morbidity and mortality associated with this condition. Adequate strategies and precautions taken during surgery such as restricting the use of non-absorbable suture material, forgoing closure of the peritoneum and using powder-free gloves etc. may further help in preventing the occurrence of intra-abdominal foreign body granulomas.

\section{Acknowledgements}

None.

\section{Conflict of interest}

No financial interest or any conflict of interest exists.

\section{References}

1. Anderson JM, Rodriguez A, Chang DT. Foreign body reaction to biomaterials. Semin Immunol. 2008;20(2):86-100.

2. Secil M, Mungan U, Yorukoglu K. Suture granuloma after orchiectomy: Sonography, doppler and elastography features. Int Braz J Urol. 2015;41(4):813-816.

3. Tsujita E, Ikeda Y, Kinjo N, et al. Suture granuloma with false-positive finding on PET/CT after gastrectomy for gastric cancer. Asian J Endosc Surg. 2015;8(4):457-460.

4. Kim SW, Shin HC, Kim IY, et al. Foreign Body Granulomas Simulating Recurrent Tumors in Patients Following Colorectal Surgery for Carcinoma: a report of two cases. Korean J Radiol. 2009;10(3):313-318.

5. Foster JA, John KB, Castro E, et al. Blepharoptosis surgery complicated by late suture migration. Am J Ophthalmol. 2000;130(1):116-117.

6. Ergin ON, Demirel M, Özmen E. An Exceptional Case of Suture Granuloma 30 Years Following an Open Repair of Achilles Tendon Rupture: A Case Report. J Orthop Case Rep. 2017;7(3):50-53.

7. Gan GC, Wastie ML. Suture granuloma following inguinal herniorrhaphy mimicking urachal tumour. J HK Coll Radiol. 2007;10:59-61.

8. Chung YE, Kim EK, Kim MJ et al. Suture granuloma mimicking recurrent thyroid carcinoma on ultrasonography. Yonsei Med J. 2006;47(5):748751.

9. Ando A, Hatori M, Hagiwara Y, et al. Imaging features of foreign body granuloma in the lower extremities mimicking a soft tissue neoplasm. Ups J Med Sci. 2009;114(1):46-51.

10. Yazici B, Sever AR, Mills P, et al. A rare cause of breast mass that mimics carcinoma: foreign body reaction to amorphous surgical material. Wien Klin Wochenschr. 2007;119(15-16):497-499.

11. Augustin G, Korolija D, Skegro M, et al. Suture granuloma of the abdominal wall with intra-abdominal extension 12 years after open appendectomy. World J Gastroenterol. 2009;15(32):4083-4086. 
12. Ollivere BJ, Bosman HA, Bearcroft PW, et al. Foreign body granulomatous reaction associated with polyethelene 'Fiberwire $(\circledR)$ ' suture material used in Achilles tendon repair. Foot Ankle Surg. 2014;20(2):e27-e29.

13. Warme WJ, Burroughs RF, Ferguson T. Late foreign-body reaction to ticron sutures following inferior capsular shift a case report. Am J Sports Med. 2004;32(1):232-236.

14. Biyani CS, Upsdell SM. An unusual foreign body in the bladder 7 years after a Stamey endoscopic bladder neck suspension. Int Urogynecol $J$ Pelvic Floor Dysfunct. 1998;9(5):303-304.

15. Imamoğlu M, Cay A, Sarihan $\mathrm{H}$, et al. Paravesical suture granuloma simulating a local recurrence of the immature sacrococcygeal teratoma. $J$ Pediatr Surg. 2005;40(3):584-585.

16. Surlin V, Georgescu E, Comănescu V, et al. Ileal iterative spontaneous perforation from foreign body granuloma: problems of histopathologic diagnosis. Rom J Morphol Embryol. 2009;50(4):749-752.

17. Tripathi PB, Kini S, Amarapurkar A. Foreign body giant cell reaction mimicking recurrence of colon cancer. Trop Gastroenterol. 2009;30(4):219-220.

18. Yazyi FJ, Canullan CM, Baglietto NF, et al. Schloffer's tumor: Case report and review of the literature. Int J Surg Case Rep. 2014;5:1234-1237.

19. Poyanli A, Bilge O, Kapran Y, et al. Foreign body granuloma mimicking liver metastasis. Br J Radiol. 2005;78(932):752-754.

20. Luijendijk RW, de Lange DC, Wauters CC, et al. Foreign material in postoperative adhesions. Ann Surg. 1996;223(3):242-248.

21. Ribalta T, McCutcheon IE, Neto AG, et al. Textiloma (Gossypiboma) mimicking recurrent intracranial tumor. Arch Pathol Lab Med. 2004;128(7):749-758

22. Epstein AJ, Russell EJ, Berlin L, et al. Suture granuloma: an unusual cause of an enhancing ring lesion in the postoperative brain. $J$ Comput Assist
Tomogr. 1982;6(4):815-817.

23. Takahara K, Kakinoki H, Ikoma S, et al. Suture Granuloma Showing False-Positive Findings on FDG-PET. Case Rep Urol. 2013;2013:472642.

24. Kikuchi M, Nakamoto Y, Shinohara S, et al. Suture granuloma showing false-positive finding on PET/CT after head and neck cancer surgery. Auris Nasus Larynx. 2012;39(1):94-97.

25. Carroll KM, Sairam K, Olliff SP, et al. Case report: paravesical suture granuloma resembling bladder carcinoma on CT scanning. Br J Radiol. 1996;69(821):476-478.

26. Ferrozzi F, Bova D, Gabrielli M. Foreign-body granuloma of the kidney: CT, MR and pathologic correlation. Eur Radiol. 1999;9:1590-1592.

27. Nagar H, Kessler A, Graif M. The role of ultrasound in the diagnosis of stitch granulomas following paediatric herniotomy. Pediatr Radiol. 1999;29(11):803-806.

28. Kentaro Miyake, Goro Matsuda, Masanori Oshi, et al. Foreign Body Granuloma Caused by Surgical Suture Material Mimicking Lymph Node Recurrence Detected by Delayed Phase FDG-PET/CT Imaging. Jpn $J$ Gastroenterol Surg. 2016;49(1):58-65.

29. De Sousa Leão G, Mororó GT, De Carvalho AMC, et al. FDG-PET/CTPositive Foreign Body Granuloma Mimicking Colon Cancer Recurrence: Case Report. J Neoplasm. 2017;2(3):15.

30. Mathai AM, Naik R, Kumar S, et al. Postoperative intestinal perforation with multiple suture granulomas. Trop Gastroenterol. 2009;30(2):102-104.

31. Martínez-Martínez A, García-Espinosa J. Non-absorbable suture granuloma mimicking a retroperitoneal metastatic implant in a patient with sigmoid neoplasm. Rev Esp Enferm Dig. 2016;108(9):579-580. 